\title{
Relational resilience as a protective factor in marital adjustment of couples with cancer: A dyadic model
}

\author{
Hudayar Cihan ${ }^{1}$, Didem Aydogan $^{2}$ \\ 'Ankara Yildirim Beyazit University, Department of Psychology, Ankara - Turkey \\ ${ }^{2}$ Adnan Menderes University, Department of Psychological Counseling and Guidance, Aydin - Turkey
}

\begin{abstract}
Objective: Understanding how the relational process progress in the face of chronic risk situation in a marriage is important for the quality of the marriage.The aim of this study is to examine the relationship between relational resilience as a protective factor and marital adjustment for couples with one spouse being a cancer, by employing a dyadic approach. In this study, relational resilience is thought to be a supportive structure in ensuring marital adjustment.
\end{abstract}

Method: One hundred fifty two couples $(n=304)$ with one of the spouses being a cancer patient participated in the study. All participants completed demographic form, relational resilience and marital adjustment measures. This study included the patients who had cancer disease and received outpatient treatment in Ankara Numune Education and Research Hospital, Dr. Ahmet Andicen Oncology Hospital and Dr. Abdurrahman Yurtarslan Oncology Training and Research Hospital. The other inclusion criteria was that the patients were married and the spouses of patients accepted to take survey as well. The study was designed according to the relational screening model. In this way, the effects of resilience of married couples on marital adjustment against cancer disease were investigated by using the Actor-Partner Interdepence Model (APIM).

Results: APIM results reveale significant actor and partner effects of cancer patients on marital relations. Results indicated that relational resilience of husband and wife in the face of cancer had positive and significant effects on marital adjustment. The research found that the partner effects on marital adjustment was higher for wives compared to husband. The results demonstrated that each person's relational resilience is the strongest predictor of their own marital adjustment and the partner's relational resilience also plays significant role in one's marital adjustment.

Conclusion: The results of the study showed the importance of the actor and partner effects of relational resilience for increasing the marital adjustment and strengthening the relationships. These results were discussed within the context of marriage counseling by taking the cultural structure into consideration.

Keywords: Actor-partner interdependence model, cancer disease, marital adjustment, protective factor, relational resilience

\section{INTRODUCTION}

In marital relationships, important or traumatic events experienced are evaluated as a milestone for relationships (1). The disease of cancer, which is one of those traumatic events, is also an important relational crisis situation for both couple and families. In the process of cancer disease, individuals experience identification of concerning symptoms, diagnostic work-up, inital diagnosis, treatment, follow-up

How to cite this article: Cihan $\mathrm{H}$, Aydogan D. Relational resilience as a protective factor in marital adjustment of couples with cancer: a dyadic model. Dusunen Adam The Journal of Psychiatry and Neurological Sciences 2020;33:281-288.

Correspondence: Hudayar Cihan, Ankara Yildirim Beyazit University, Faculty of Human and Social Science, Department of Psychology, Esenboga Campus Cubuk, Ankara - Turkey

E-mail: hudayarcg@ybu.edu.tr

Received: March 24, 2020; Revised: April 28, 2020; Accepted: August 15, 2020 
surveillance, adjustment to survivorship and recurrence or progression of disease (2). In this regard, resilience-based approaches aim to reinforce familial interactional processes against those coercive experiences $(1,3)$. Particularly, when facing with stressful conditions, resilient families can retain their balance, adapt to changes and cope with challenges whereby adjusting with a crisis (3).

Resilience is a dynamic process involving positive adaptation in the face of experienced negativity (4). Resilience also includes an individual's ability to maintain psychological and physical functioning when confronted with stressful life events and adversity $(5,6)$. In order to mention psychological resilience, the emerging adaptation or positive development needs to be revealed in the conditions which are considered risky (7). The concept of resilience which is closely related to post-traumatic growth offers an approach which assesses how to overcome stress, negative experiences and traumas such as epidemics, chronic disases, and economic instability. Researches have emphasized that the traumatic characteristics of a life-threatening illness as cancer and demonstrated how cancer patients exhibit responses consistent with psychological trauma $(8,9)$.

In a research study, women with breast cancer were found to display resilient characteristics and motivated to cope with this disease, focused on getting good and fast results and did not show signs of mental disorder (10). Cancer is a disease influencing both partners, so it is defined as a dyadic stressor in a relationship $(11,12)$. Change in a member of family affects other family members and in order to retain homeostasis, compensatory changes take place in the family system (13). Diagnosis of cancer has an influence on all family members, but at the same time, affects their interaction with each other and family functioning (14-16). Couples try to give a meaning to this negative situation they experience on one hand and they face with conditions like adapting to changing roles, planning future, child care or economical difficulties on the other hand. Difficulties experienced during process of treatment, medical processes and dynamics of relationship are factors affecting coping of the individuals and their partners. Partners try to overcome difficulties and experience anxiety for possibility of losing their partner at the same time and struggle to give emotional and practical support to them also (17). In the related literature, there are studies examining dyadic coping and marital adjustment and quality in cancer and chronic disease (e.g. cardiac disease) situations (18-20).
It is quite new to evaluate the characteristic of resilience within the context of relationship and marriage. Researchers interpret relational resilience against the backdrop of Relational Cultural Theory, (RCT) (21) and relational abilities (22), marital resilience (18) and couple resilience (23). Resilience is a relational phenomenon emphasizing supported vulnerability, reciprocal emphatetic participation, relational trust, mutual development and tackling together mutual support and relational awareness when there is a disconnection in relationship process of couple (21). Relational resilience in close relationships, a colloborative approach, common experiences, an experience of togetherness, belongingness to relationship and reciprocal support processes are important in facilitating relationship (22). In the meantime, in related literature, "The Relationship Intimacy (TRI)" model is important for psychological and marital adaptation of couples to accept cancer as a stressor factor influencing both partners and to try to maintain and improve their relationship (24).

Some studies reveal that cancer does not always leave a negative mark on individual and could make important contributions to the individual in this process. In a research study, results demonstrated an improvement in intimacy between women with breast cancer and their husbands (6). Awareness related to cancer can make partners think on how to cope with this situation as a couple and how to maintain normality and focus on their relationships (25). The adaptation of couple to cancer and treatment process depends on the approval of the situation by both partners, sharing of emotional sadness and processes of coping (26). In another research study, it was found that stress experienced by one partner increases the stress of other partner (27). At the same time, less intimacy and romantic interaction resulted in emotional distress and decreased marital satisfaction among breast cancer patients and their husbands $(28,29)$. In the meantime, in a study conducted with couples who experience prostate or breast cancer, it was revealed that psychological distress each partner feel has an important role both on the life quality of patient and partner $(16,30)$. On the other hand, although the patients with prostate cancer reported that the marital relationship remained unchanged during the follow-up period (6 months later), their spouses reported that the marital relationship suffered (24).

Engaging in joint coping styles is important in creating a sense of "normality" in relationship process of the couple in stressful time periods (12). It was found 
that in patients with prostate cancer and their partners, colloborative or joint coping was found to decrease emotional distress (31) and sharing of relational problems and anxieties, reciprocal constructive communication was also found to be important in terms of relational quality of the relationship (32).

Thus far, studies focusing on possible direct association of relational resilience and marital adjustment are limited in number. Chronic diseases have an influence on both partners because one partner's stress affects the other partner (33). Therefore, it is necessary to evaluate both partners in terms of relational resilience and marital adjustment. Taking the relevant literature into account, general consensus can be found concerning the mutual beneficial effects that relational resilience can provide both the individual with cancer and his/her partner, particularly when dealing with marital adjustment. There are studies in literature evaluating disease of cancer by mutual effect model within the context of couple relationship $(16,25)$. The researches investigating relational resilience in marital relationship in the face of important risky situations are extremely rare in Turkey $(34,35)$. Taking into account these explanations, the primary goal of the current study was to examine the effects of relational resilience on the marital adjustment of couples dealing with cancer. The aim of this research was to examine the effects of relational resilience on the marital adjustment of couples dealing with cancer. Drawing from existing research and theoretical explanations, it was hypothesized that one's own relational resilience would be positiviely related to one's own marital adjustment and to that of the partner.

\section{METHOD}

\section{Participants}

One hundred fifty two couples ( $\mathrm{n}=304$ individuals) participated in the study and one partner $(n=152)$ in each couple had a diagnosis of cancer. Inclusion criterias for participants were that one of the partners should have a diagnosis of cancer and receiving outpatient treatment and both partners had to be 18 years of age or over. The other inclusion criteria was that the patients were married and the spouses of patients accepted to take survey as well. The mean age of female participants was 49 years (standard deviation $[S D]=10.26$, range 24 to 70 ), and the mean age of male participants was 53.44 years $(\mathrm{SD}=11.09$, range 24 to 84). The length of marriages varied between 1 and 54 years $(M=28.37, S D=11.90)$. Number of childrenof participants in the study group range between 0 and 8 with an avarage of 2.68 .

The education level of female participants was literate $12(5.7 \%)$, non literate $9(4.3 \%)$, primary school $86(41.1 \%)$, secondary school $22(10.5 \%)$, high school $43(20.6 \%)$, university $28(13.4 \%)$ and graduate $4(1.9 \%)$. The education level of male participants was literate $5(2.4 \%)$, non literate $1(0.5 \%)$, primary school 64 (30.6\%), secondary school 27 (12.9\%), high school 65 (31.1\%), university 37 (17.7\%) and graduate 7 (3.3\%). The female participants receiving psychological support were $43(20.6 \%)$, and the female participants not receiving psychological support were 163 (78\%). The male participants receiving psychological support were $26(12.4 \%)$, and the male participants not receiving psychological support were 179 (85.6\%). The majority of the female participants had breast cancer 24 (11.5\%), colon cancer $8(3.5 \%)$, uterus cancer 7 (3.5\%), stomach cancer $6(2.9 \%)$, leucaemia cancer 5 (2.5\%), chest cancer 4 (1.9\%), lung cancer 3 (1.5\%) and liver cancer 3 (1.5). The majority of the male participants had lung cancer $15(7.7 \%)$, stomach cancer 12 (5.7\%), colon cancer 10 (4.5\%), leucaemia cancer $11(5.3 \%)$ and prostate cancer $4(2 \%)$.

\section{Procedure}

The research group of this study is consisted of married couples in which one partner has a diagnosis of cancer. In the research process, necessary permissions were taken from Ethical Comitee of Ankara Yıldırım Beyazıt University. In the next stage, necessary legal permissions were taken from Ankara Numune Education and Research Hospital, Dr. Ahmet Andicen Oncology Hospital and Dr. Abdurrahman Yurtarslan Oncology Education and Research Hospital and data collection started.

In the study, data collection tools were applied to voluntary married couples by interviewers. Couples participating in the study were informed about the aim of research and informed consent forms were signed. Participants were considered eligible only if both members of dyad agreed to participate. No names or nicknames were taken in written form from participants. Interventions were made to partners seperately and one application lasted about 40-45 mins for each participant. The data collection period lasted ten months.

\section{Measures}

Both husbands and wives completed demographical information forms, the Relational Resilience Scale and the Marital Adjustment Scale. 
Demographic Information Form: Participants were asked to provide both personal information (e.g. age, gender) and marriage information (e.g., length of marriage and number of children).

Relational Resilience Scale (RRS): The RRS is a self-report, multidimensional scale measuring couple's ability to recover after traumatic life experiences with 27 item which was developed by Aydogan and Ozbay (36). There are four subscales of RRS: actor (e.g. item, I give hope to my partner that everything will be better), partner (e.g. item, my partner gives me power to hold on to life again), union (e.g. item, My partner and I mutually care about our feelings), and spirituality (e.g. item, I ask my partner top ray in order for everything to go well). RSS is a seven-point likert type scale in which participants choose from 1 (never) to 7 (always). Subscale scores are added to get a total relational resilience score index. The total score ranges from 27 to 189 . The higher the total score is, the higher the resilience level of the couple is. Cronbach's alphas were 0.93 for actor, 0.90 for partner, 0.90 for union, 0.95 for spirituality and 0.96 for the overall scale. In the current study, all 27 items were utilized as an index of relational resilience. Alpha was 0.96 for females and 0.96 for males in this study.

Marital Adjustment Test (MAT): The MAT is developed by Locke and Wallace in 1959 and has 15 items and it is adapted to Turkish language by Tutarel Kislak (37) and tested in terms of reliability and validity. Total scores range from 1 to 60 , the higher the score is, the better the marital adjustment and vice versa is. Scale focuses not only on marital adjustment but also on the degree of consensus between spouses on several subjects like family budget, expression of feelings, friends, sexuality, life philosophy, confidence and problem-solving and on how partners have a relationship in their spare times and outdoor activities. Internal consistency coefficient of the scale was found as 0.84 and split half reliability was found as 0.84 in reliability measures. Test-retest reliability measures were made and correlation coefficient was found as 0.57. Between the Interpersonal Relationship Scale and MAT total scores, correlation coefficient was found as 0.12 which is used to measure criterion related validity and for Relationship Pressure Scale total scores, correlation coefficient was found as -0.54 (3). The Cronbach's alpha was calculated for females and males and found to be 0.85 and 0.81 respectively.

\section{Data Analytic Strategy}

Conceptually, dyadic data provides a unique opportunity to study truly relational phenomenon and the relative influence of both dyad members. The Actor-Partner Interdependence Model (APIM) has been utilized to analyze the dyadic data (38). The APIM allows for a relational examination of the influence of both the individual and his/her partner on outcome variables (39). Within the APIM model, examining actor and partner influences give us more detailed and reliable information on relational situations. The APIM is particularly suitable as a model for analysis, as the present study was focused on the interdependence of a couple's relational resilience on marital adjustment. Actor effect; the relationship between persons' scores on a predictor variable and their own outcomes, controlling for the other persons' scores on the same predictor variable. Partner effect; the relationship between persons' scores on a predictor variable and their partners' outcomes, controlling for the other persons' scores on the same predictor variable. The Actor-Partner Interdependence Model approach was applied to the present study to examine the effects of perceived relational resilience on couple's marital adjustment.

Relationship between relational resilience and marital adjustment was examined by using Pearson Correlation analysis in the study. APIM analysis was applied by using path analysis to test the structural model which was proposed to examine actor and partner effects. While path analysis was carried out on the data, analysis was carried out through observed variables, in other words, on the total score obtained from the scales. In the interdependence analysis, the covariation across individuals was also calculated. However, this model is a saturated model and fit indices are not reported (40). Fit indices (RMSEA, CFI, and NNFI) were taken into account to determine whether the proposed path model was working. Data analysis was carried out using SPSS 21.0 and AMOS 16 statistics programs.

\section{RESULTS}

\section{Preliminary Analyses}

A total of 152 couples participated in this study. First of all, in Table 1, before examining actor-partner influences between couples, relationships between variables were examined using Pearson product moment correlation. Correlations among main variables for husband and wife are presented in Table 1. One's own relational resilience was positively related to one's own marital adjustment for both men and women participants. As seen in Table 1, there is a high level of correlation 
Table 1: Correlations between relational resilience and marital adjustment among husband and wife

\begin{tabular}{lcccc} 
Variables & $\mathbf{1}$ & $\mathbf{2}$ & $\mathbf{3}$ & $\mathbf{4}$ \\
\hline 1 Relational resilience_W & - & $0.44^{* *}$ & $0.69^{* *}$ & $0.48^{* *}$ \\
2 Relational resilience_H & $0.44^{* *}$ & - & $0.41^{* *}$ & $0.63^{* *}$ \\
3 Marital adjustment_W & $0.69^{* *}$ & $0.41^{* *}$ & - & $0.53^{* *}$ \\
4 Marital adjustment_H & $0.48^{* *}$ & $0.63^{* *}$ & $0.53^{* *}$ & - \\
\hline
\end{tabular}

** $\mathrm{p}<0.01, \mathrm{H}$ : Husband, W: Wife

between wife's relational resilience and their own marital adjustment $(\mathrm{r}=0.69, \mathrm{p}<0.01)$. In addition, reasonable level of positive sided relationships were found between husband's relational resilience and their marital adjustment $(\mathrm{r}=0.63, \mathrm{p}<0.01)$. At the same time, there were avarage level positive-sided relationships between wife relational resilience and husband relational resilience $(\mathrm{r}=0.44, \mathrm{p}<0.01)$, and wife marital adjustment and husband marital adjustment $(\mathrm{r}=0.53$, $\mathrm{p}<0.01)$.

\section{Relational Resilience and Marital Adjustment: APIM Model}

In the research study, APIM model which try to explain marital adjustment with relational resilience in case of a cancer couples experience is used and analysed with path analysis. In APIM model, actor and partner relationships were examined by relating errors between relationships between women's and men's relational resilience connections and resulting variables (of marital adjustment of women and men) in Figure 1.

For actor and partner influences for both women and men, non-standardized regression coefficients (B), standard errors, $\mathrm{t}$ and $\mathrm{p}$ values and standardized regression coefficientsare presented in Table 2.

When actor influences are examined from Table 2, it can be seen that relational resilience that women and men have by ownselves has an important influence directly on their marital adjustment. Actor influence of relational resilience on marital adjustment for women was found as $\mathrm{B}=0.64, \mathrm{p}<0.001$ and $\mathrm{B}=0.51, \mathrm{p}<0.001$ for men. When partner effects are evaluated, it is observed that relational resilience of women explains marital adjustment of men significantly $B=0.23, p<0.05$, in addition, relational resilience of husband has a significant effect on wife's marital adjustment $B=0.11$, $\mathrm{p}<0.001$. These results reveal that increase in relational resilience of women and men as individuals also increase marital adjustment of partners. The overall APIM model with distinguishable dyads is a saturated model $\left(\chi^{2} / \mathrm{df}[0]=0.000\right)$, thus measures of fit cannot be computed (41). In the final proposed model, RMSEA was calculated as 0.02 and the values of CFI and NNFI were calculated as 0.99 . The value of RMSEA approaches 0 and the value of CFI and NNFI approach 1, which indicates that the proposed model is fully saturated $(42,43)$. Root mean square residual values was given 0.00 for the APIM.

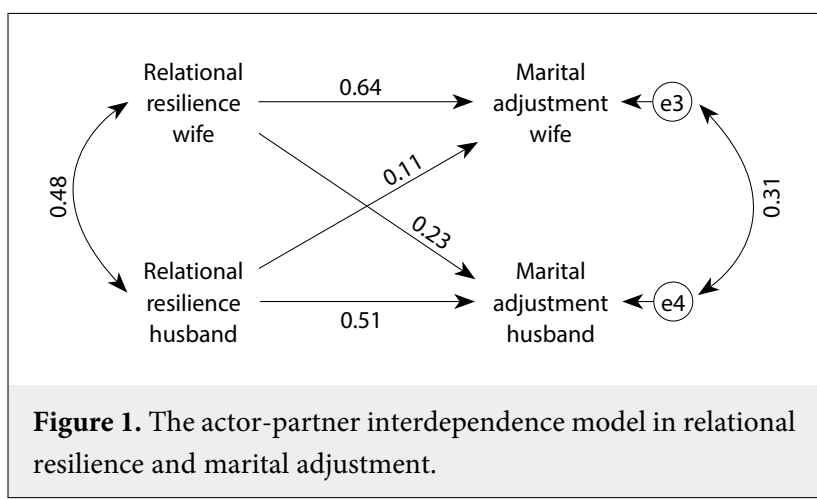

Table 2: Partner effects of men and women Effect

B

Sh $\mathbf{t}$ p Standardized regression coefficients

\section{Actor effects}

Relational resilience --->Marital adjustment

Women actor effect

Men actor effect

Relational resilience --->Marital adjustment

Women partner effect

Men partner effect

$\begin{array}{lccc}0.02 & 11.380 & <0.001 & 0.64 \\ 0.02 & 8.577 & <0.001 & 0.51 \\ 0.02 & 3.812 & 0.04 & 0.23 \\ 0.02 & 1.986 & <0.001 & 0.11\end{array}$

64 


\section{DISCUSSION}

This study investigates relationships between relational resilience as a protective factor and marital adjustment in a dyadic approach in couples in which one partner have a diagnosis of cancer. Our findings demonstrate that each person's relational resilience is the strongest predictor of their own marital adjustment and the partner's relational resilience also plays significant role in one's marital adjustment. Especially understanding couple's resilience characteristic and how this characteristic affect marital adjustment is thought to be necessary for interventions to develop and improve marital relationships. The present study's hypothesis on the link between one's own relational resilience and one's own marital adjustment was confirmed. Wife and husband's having relational resilience significantly improves one's marital adjustment at the actor level. As could be seen in some studies, positive relationship between one's own dyadic coping significantly enhances one's own relationship satisfaction at the actor level $(44,45)$.

It was hypothesized that partner effects were confirmed in the associations between relational resilience and marital adjustment. More specifically relational resilience in wife and husband was shown to improve their partner's marital adjustment. It can be said that disease of cancer cause individual and relational changes in marriage and relational resilience aspect providing coping against this disorder is a protective factor for marital adjustment of both individual and also his/her partner. Consequently, it can be inferred that couples in research group are in a developing relationship, open to each other, caring about needs and emotions of the other partner, and have characteristics providing relational resilience including reciprocal support and emphaty. In this situation, it can be seen that couples' having high level of marital adjustment is important in terms of providing a sense of being a couple. Studies in relevant literature reveal that existence of resilience in cancer disease is important in terms of individual's positive development and improvement (10). As a result of this study, existence of actor-partner influences in marital adjustment is supported by other studies in terms of systems approach $(14,15)$.

It is difficult to evaluate women's and men's reactions against a negative experience out of cultural context. Turkish culture in which the study group also included is a society that family and social interaction, interpersonal commitment and reciprocal dependence takes place in the foreground. In the context of collectivism (a culture of relationality), family is in commitment with other relatives and families. This is a familial and individual commitment in material and emotional terms. Psychological/emotional commitment model is common in developed and urbanized regions of societies with a cultureof relationality (collectivism). In this model, there is a reciprocal dependence in emotional domain and an independence of both individual and family in material domain (46). Especially in crisis conditions for couples, like cancer, psychological and sometimes economical support coming from these systems is important in terms of keeping these people on their feet, improving their relationships and contributing to their resilience. So, it is important to evaluate this result in terms of relational cultural approach. In RTC model, it is emphasized that individual develops by reciprocal relationships with other people rather than individualization, disintegration and autonomy (21)

In the research study, it was found that marital adjustment of women and men influences each other reciprocally. Relevant literature also shows that both individuals and their partners are influenced when they face with a cancer disease (16,30). Actually, this finding is important in term of developing a couple identity. In a research study, it was found that if married couples take joint action by engaging in common positive dyadic coping in managing stressful condition resulting from cancer, they improve and maintain reciprocal adjustment and at the same time, present this characteristic in different aspects of marriage (34).

In the meantime, another important finding obtained from this study is as follows; partners' relational resilience is an important protective factor for their own marital adjustment. This result also is an indicator of that both women and men can cope with this compelling experience and can present health care and support for their partners. This finding is supported by relevant literature focusing on explanations of couples on their adaptation to cancer. It is underlined in the model that both partners' efforts to maintain and improve relationship have an important role in marital adjustment (47). In this respect, RTC approach supports that if partners' reciprocal influences are on the positive side, individual and relational development and improvement can be obtained (21).

This study is limited to variables about marriage like relational resilience and marital adjustment of the individual and his/her partner. Future research can focus on evaluating contextual factors more extensively with relational resilience. For example; individual factors, family factors and other relationships types and cultural structure contexts. Particularly investigating 
relational resilience within the frame of individual, familial and environmental factors would contribute to understand marriage relationship after a trauma experience. There is no limitation in terms of types of cancer in this study. However, it is thought that different types of cancers; for example women with breast cancer or men with prostate cancer could be effective in marriage relationship process. In this respect, it is important in the future to make research studies according to different types of cancer in terms of evaluating marriage relationship within the context of relational resilience. Finally, another limitation of this study, cancer patients with psychiatric illness or symptoms were not excluded from the study. In future studies, relational resilience studies can be planned in cancer patients with and without psychiatric diagnosis.

\begin{tabular}{|c|c|c|}
\hline \multicolumn{2}{|c|}{ Contribution Categories } & Author Initials \\
\hline \multirow{3}{*}{ Category 1} & Concept/Design & H.C., D.A. \\
\hline & Data acquisition & H.C., D.A. \\
\hline & Data analysis/Interpretation & D.A. \\
\hline \multirow{2}{*}{ Category 2} & Drafting manuscript & D.A., H.C. \\
\hline & Critical revision of manuscript & H.C., D.A. \\
\hline Category 3 & Final approval and accountability & H.C., D.A. \\
\hline \multirow{2}{*}{ Other } & Technical or material support & D.A., H.C. \\
\hline & Supervision & H.C. \\
\hline
\end{tabular}

Ethics Committee Approval: This study was approved by Ankara Yildirim Beyazit University Ethics Committee (Date: 01/12/2015, Number: 3).

Informed Consent: Written informed consent of the patient has been obtained.

Peer-review: Externally peer-reviewed.

Conflict of Interest: No conflict of interest.

Financial Disclosure: This study was funded by Ankara Ylldırım Beyazit University, Scientific Research Projects Department.

\section{REFERENCES}

1. Walsh F. The concept of family resilience: crisis and challenge. Fam Process 1996; 35:261-281.

2. Deshields TL, Heiland MF, Kracen AC, Dua P. Resilience in adults with cancer: development of a conceptual model. Psychooncology 2016; 25:11-18.

3. McCubbin MA, McCubbin HI. Family coping with health crises: The resiliency model of family stress, adjustment, and adaptation: In Danielson CB, Hamel-Bissell B, Winstead-Fry P (editors). Families, health \& illness: Perspectives on coping and intervention, New York: Mosby, 1993, 21-64.

4. Luthar SS, Cicchetti D, Becker B. The construct of resilience: a critical evaluation and guidelines for future work. Child Dev 2000; 71:543-562.
5. Bonanno GA, Westphal M, Mancini AD. Resilience to loss and potential trauma. Annu Rev Clin Psychol 2011; 7:511-535.

6. Zeidner M, Kloda I, Matthews G. Does dyadic coping mediate the relationship between emotional intelligence (EI) and marital quality? J Fam Psychol 2013; 27:795-805.

7. Masten A.S. Ordinary magic-resilience in development. New York: The Guilford Press, 2014.

8. Chan $\mathrm{CMH}$, Ng CG, Taib NA, Wee LH, Krupat E, Meyer F. Course and predictors of post-traumatic stress disorder in a cohort of psychologically distressed patients with cancer: A 4-year follow-up study. Cancer 2018; 124:406-416.

9. Swartzman S, Booth JN, Munro A, Sani F. Posttraumatic stress disorder after cancer diagnosis in adults: A meta-analysis. Depress Anxiety 2017; 34:327-339.

10. Giacomo DD, Cannita K, Ranieri J, Cocciolone, V, Passafiume D, Ficorella, C. Breast cancer and psychological resilience among young women. J Psychopathol 2016; 22:191-195.

11. Bodenmann, G. Dyadic coping and its significance for marital functioning: In Revenson T, Kayser K, Bodenmann G (editors). Couples coping with stress: Emerging perspectives on dyadic coping. Washington, DC: American Psychological Association, 2005.

12. Badr H, Carmack CL, Kashy DA, Cristofanilli M, Revenson TA. Dyadic coping in metastatic breast cancer. Health Psychol 2010; 29:169-180.

13. Mehta A, Cohen SR, Chan LS. Palliative care: a need for a family systems approach. Palliat Support Care 2009; 7:235-243.

14. Acitelli LK, Badr H. My illness or our illness? Attending to the relationship when one partner is ill: In Revenson T, Kayser K, Bodenmann G (editors). Emerging perspectives on couples' coping with stress. Washington, DC: American Psychological Association, 2005,121-136.

15. Alderfer MA, Kazak AE. Family issues when a child is on treatment for cancer: In Brown $\mathrm{R}$ (editor). Comprehensive handbook of childhood cancer and sickle cell disease: $\mathrm{A}$ biopsychosocial approach New York, NY: Oxford University Press, 2006, 53-74.

16. Kim Y, Kashy DA, Wellisch DK, Spillers RL, Kaw CK, Smith TG. Quality of life of couples dealing with cancer: dyadic and individual adjustment among breast and prostate cancer survivors and their spousal caregivers. Ann Behav Med 2008; $35: 230-238$

17. Kalayjian A. Coping with cancer: the spouses' perspective. Arch Psychiat Nurs 1989; 3:166-172.

18. Canary D, Stafford L, Semic BA. A panel study of the associations between maintenance strategies and relational characteristics. J Marriage Fam 2002; 64:395-406.

19. Watts KJ, Sherman KA, Mireskandari S, Meiser B, Taylor A, Tucker K. Predictors of relationship adjustment among couples coping with a high risk of developing breast/ovarian cancer. Psychol Health 2011; 26:21-39.

20. Meier C, Bodenmann G, Mörgeli H, Jenewein J. Dyadic coping, quality of life, and psychological distress among chronic 
obstructive pulmonary disease patients and their partners. Int J Chron Obstruct Pulmon Dis 2011; 6:583-596.

21. Jordan JV. Relational resilience in girls: In S Goldstein, RB Brooks (editors). Handbook of resilience in children. New York, NY: Springer Science/Business Media, 2005; 79-90.

22. Connolly CM. A qualitative exploration of resilience in long-term Lesbian couples. The Fam J 2005; 13: 266-280.

23. Skerrett K. Resilience in couples: A view of the landscape: In Skerrett K, Fergus K (editors). Couple resilience: Emerging perspectives. New York, US: Springer Science, 2015, 3-22.

24. Harju E, Rantanen A, Helminen M, Kaunonen M, Isotalo $T$, Åstedt-Kurki P. Marital relationship and health-related quality of life of patients with prostate cancer and their spouses: A longitudinal clinical study. J Clin Nurs 2018; 27:2633-2639.

25. Manne SL, Siegel S, Kashy D, Heckman CJ. Cancer-specific relationship awareness, relationship communication, and intimacy among couples coping with early stage breast cancer. J Soc Pers Relat 2014; 31:314-334.

26. Zunkel G. Relational Coping Processes. J Psychosoc Oncol 2002; 20:39-55.

27. Manne S. Cancer in the marital context: a review of the literature. Cancer Invest 1998; 16:188-202.

28. Erdogan E, Karakas SA. Analysis of sexual life quality and marital satisfaction in women with breast cancer: Turkish sample. Int J of Caring Sci 2019; 12:1497-1505

29. Mushtaq N, Ali R. Marital satisfaction of breast cancer patients and their spouses: a qualitative study. Pakistan Journal of Women's Studies: Alam-E-Niswan 2019; 26:65-87.

30. Morgan MA, Small BJ, Donovan KA, Overcash J, McMillan S. Cancer patients with pain: the spouse/partner relationship and quality of life. Cancer Nurs 2011; 34:13-23.

31. Berg CA, Wiebe DJ, Butner J, Bloor L, Bradstreet C, Upchurch $\mathrm{R}$, et al. Collaborative coping and daily mood in couples dealing with prostate cancer. Psychol Aging 2008; 23:505-516

32. Manne S, Badr H, Zaider T, Nelson C, Kissane D. Cancerrelated communication, relationship intimacy, and psychological distress among couples coping with localized prostate cancer. J Cancer Surviv 2010 Mar; 4:74-85

33. Berg CA, Upchurch R. A developmental-contextual model of couples coping with chronic illness across the adult life span. Psychol Bull 2007; 133:920-954.
34. Aydogan D, Ozbay Y. Mediation role of dyadic coping on parenting stress and relational resilience in couples. Marriage and Fam Rev 2018; 54:128-147.

35. Aydogan D, Dincer D. Creating resilient marriage relationships: Self-pruning and the mediation role sacrifice with satisfaction. Current Psychol 2020; 39:500-510.

36. Aydogan D, Ozbay Y. Development of relational resilience scale for married individuals. 13th National Congress of Psychological Counseling and Guidance. Proceeding Book, 2015, 8-10. (Turkish)

37. Tutarel-Kislak S. Reliability and validity of Marital Adjustment Test. 3P Psychiatry, Psychology Psychopharmacology 1999; 7:5565. (Turkish)

38. Kenny DA, Cook W. Partner effects in relationship research: Conceptual issues, analytic difficulties, and illustrations. Pers Relationship 1999; 6:433-448.

39. Cook W, Kenny D. The Actor-partner interdependence model: A model of bidirectional effects in developmental studies. Int J Behav Dev 2005; 29:101-109.

40. Chow M C, Tan C C. Attachment and commitment in dyadic friendships: Mediating roles of satisfaction, quality of alternatives, and investment size. J Relationships Research 2013; 34:1-11.

41. Kenny DA, Kashy DA, Cook WL. Dyadic data analysis. New York: The Guildford Press; 2006.

42. Schumacker ER, Lomax GR. A beginner's guide to structural equation modeling. NJ: Erlbaum, Mahwah; 1996.

43. Tabachnick BG, Fidell LS. Using Multivariate Statistics. Fourth ed., Boston: Allyn and Bacon; 2001.

44. Bodenmann G, Charvoz L, Cina A, Widmer K. Prevention of marital distress by enhancing the coping skills of couples: 1-year follow-up-study. Swiss J Psychol 2001; 60:3-10.

45. Bodenmann G, Shantinath SD. The Couples Coping Enhancement Training (CCET): A new approach to prevention of marital distress based upon stress and coping. Fam Relat 2004; 53:477-484

46. Kagitcibasi C. Self, family and human development: Theory and applications in cultural psychology. Fourth ed., Koc University Publication, 2017. (Turkish)

47. Manne S, Badr H. Intimacy and relationship processes in couples' psychosocial adaptation to cancer. Cancer 2008; 112(Suppl.11):2541-2555. 